\title{
GCU
}

Glasgow Caledonian

University

University for the Common Good

\section{Rise in testing and diagnosis associated with Scotland's Action Plan on hepatitis C and introduction of dried blood spot testing}

McLeod, Allan; Weir, Amanda; Aitken, Celia; Gunson, Rory; Templeton, Kate; Molyneaux, Pamela; Mclntyre, Paul; McDonald, Scott; Goldberg, David; Hutchinson, Sharon

Published in:

Journal of Epidemiology and Community Health

DOI:

10.1136/jech-2014-204451

Publication date:

2014

Document Version

Author accepted manuscript

Link to publication in ResearchOnline

Citation for published version (Harvard):

McLeod, A, Weir, A, Aitken, C, Gunson, R, Templeton, K, Molyneaux, P, Mclntyre, P, McDonald, S, Goldberg, D \& Hutchinson, S 2014, 'Rise in testing and diagnosis associated with Scotland's Action Plan on hepatitis C and introduction of dried blood spot testing', Journal of Epidemiology and Community Health, vol. 68, no. 12, pp. 1182-1188. https://doi.org/10.1136/jech-2014-204451

\section{General rights}

Copyright and moral rights for the publications made accessible in the public portal are retained by the authors and/or other copyright owners and it is a condition of accessing publications that users recognise and abide by the legal requirements associated with these rights.

Take down policy

If you believe that this document breaches copyright please view our takedown policy at https://edshare.gcu.ac.uk/id/eprint/5179 for details of how to contact us. 


\section{Rise in testing and diagnosis associated with Scotland's Action Plan on Hepatitis $C$ and introduction of dried blood spot testing}

\section{INTRODUCTION}

An estimated 210,000 people in the UK $(0.4 \%$ and $0.8 \%$ of the adult population in England and Scotland, respectively) are chronically infected with the hepatitis $\mathrm{C}$ virus (HCV); as many as half are undiagnosed.[1] As these individuals remain infectious, are at risk of developing liver disease and may not receive treatment this is a major issue for the control and management of the epidemic.

In Scotland, there have been several national initiatives with the aim of increasing $\mathrm{HCV}$ testing and diagnosis, as summarised in Appendix 1. During the early to mid 2000s, the Scottish Needs Assessment Programme report, the Royal College of Physicians consensus statement and SIGN guidelines established recommendations for testing: people who inject drugs (PWID), organ donors, HIV positive individuals, children of HCV positive mothers, sexual and household contacts of cases, and those who received dental or medical treatment in high prevalence countries with poor infection control.[2- 4] The SIGN guidelines suggested high priority for case finding should be given to former PWID, especially those over 40 years, who may have more advanced disease and benefit from treatment.

It was not until the launch of Scotland's Hepatitis C Action Plan, however, that additional resources were allocated to develop HCV services: $£ 2$ million during Phase I and $£ 37$ million during Phase II. One of the key aims of the Action Plan was to identify undiagnosed infections. During Phase I, NHS Boards considered ways of improving accessibility of testing services, and to identify and offer HCV testing to at risk groups.[5] Phase II included awareness raising activities - targeted at professionals, particularly general practitioners, and at risk individuals - to promote 
HCV testing.[6] Minimally invasive dried blood spot (DBS) sampling was also introduced during Phase II in community drug services to increase access of testing. In Scotland, DBS antibody testing is undertaken using a modified ORTHO HCV version 3.0 ELISA kit with close to $100 \%$ sensitivity and $100 \%$ specificity. $[7,8]$ To monitor the performance of these actions Health Protection Scotland (HPS) established surveillance of HCV testing in Scotland. We utilise these data to examine i) trends in $\mathrm{HCV}$ testing in Scotland and ii) whether there has been an increase in people being tested for, and diagnosed with, $\mathrm{HCV}$ in Scotland following the launch of the government-funded Hepatitis C Action Plan.

\section{METHODS}

\section{Data source}

The West of Scotland Specialist Virology Centre (WoSSVC); East of Scotland Specialist Virology Centre (EoSSVC); Department of Medical Microbiology at Aberdeen Royal Infirmary and Ninewells Hospital \& Medical School provided HPS with retrospective data on all anti-HCV tests undertaken between January 1999 and December 2011. Almost three-quarters of new HCV diagnoses in Scotland are reported from the NHS boards served by these laboratories.[9]

Data provided includes: forename, surname, sex, date of birth; either Community Health Index (CHI) number, hospital/clinic number, or genitourinary medicine (GUM) clinic number; requesting clinician information (address and health board); and test information (specimen date and anti-HCV result).

\section{Preparation of data}


As a standardised request form is not used for HCV testing, risk information is available only when volunteered at the time of the test request. Free-text, clinical details fields were searched for mention of PWID risk. Ethnicity (categorised as "South Asian" or "Other") was determined using the name recognition software, Nam Pehchan.[10] A soundex code, generated using the surname, and the forename initial were retained; full names were excluded from the dataset for the subsequent analysis. Approval for data collection and analysis was given by the Clinical Governance Committee at Health Protection Scotland.

Tests of children aged less than two years old were excluded as these may indicate the presence of passively-acquired maternal antibodies rather than true infection. [11] Tests requested in occupational health, fertility clinics, renal units, and confirmatory tests were excluded. Positive results were laboratory confirmed and unconfirmed or equivocal results were also excluded.

Test results belonging to the same individual were matched deterministically using one of four criteria: (i) sex, date of birth, forename initial and surname soundex; (ii) CHI number; (iii) sex, date of birth, and hospital/clinic number and (iv) source of request and GUM number for tests requested in the GUM setting. Almost all (97\%) test records had sufficient data to match on at least one of these criteria.

Derived fields were calculated: anti-HCV results were recoded "positive" or "negative"; age at the time of test was generated using date of birth and date of test and categorised into eight age groups. Setting was determined using the address of test referral, and categorised as GP, hospital, GUM clinic, drug service, prison, and other/not known.

\section{Statistical analysis}


Segmented regression analysis was used to evaluate the effect of Scotland's $\mathrm{HCV}$ Action Plan on the number of a) anti-HCV tests and b) anti-HCV positive tests.[12] The data were split into 6 monthly intervals and categorised as pre-Action Plan (January 1999 to December 2006) or Action Plan (January 2007 to December 2011). The Action Plan was launched in late 2006 so January 2007 is used as the change point. Pre-Action Plan trends are compared to Action Plan trends and the level change in anti-HCV testing, at the change, is estimated. Negative binomial models were fitted to account for overdispersion in the data.[12, 13]

The model takes the form:

$$
\log \left(Y_{t}\right)=\beta_{0}+\beta_{1}{ }^{*} \text { Time }_{t}+\beta_{2} * A P_{t}+\beta_{3}{ }^{*} \text { TimeAP }_{t}+e_{t}
$$

where $Y t$ is the mean number of tests per 6 monthly interval $t$; Time counts the number of intervals $t$ since the beginning of observation ; AP is an indicator variable ( 0 before the change point and 1 after); TimeAP counts the number of intervals $t$ during the Action Plan segment; $\beta_{0}$ is the baseline number of tests at the start of observation ; $\beta_{1}$ describes the trend in testing pre- Action Plan; $\beta_{2}$ estimates the level change in the number of tests; $\beta_{3}$ estimates the change in trend in testing during the Action Plan compared with the trend pre- Action Plan; $e_{t}$ is the model error term. The trend in testing during the Action Plan is calculated as $\beta_{1}+\beta_{3}$. A second model comparing the trends before and after the introduction of DBS testing in 2009, for all tests and those from drug services was analysed. Results are presented in the form of rate ratios (RR) with $95 \%$ confidence intervals and associated p-values.

\section{RESULTS}

\section{Overall trends in, and characteristics of, those tested}


The annual number of people tested for anti-HCV increased from 15,515 in 1999 to 30,906 in 2011 (Figure 1), representing a total of 297,689 tests. Among those tested, 9\% (27,966) tested anti-HCV positive, 55\% $(164,147)$ were male, $60 \%$ $(177,665)$ aged $20-49$ years at the time of their first test, $49 \%(145,140)$ and $32 \%$ $(93,954)$ were first tested in the hospital and general practice settings, respectively

(Table 1). Three percent (9332) were of South Asian ethnicity. Injecting drug use was reported with $9 \%(25,580)$ of all anti-HCV tests, and $34 \%$ of positive anti-HCV tests (indicating considerable under-reporting as more than $80 \%$ of positive tests would be expected to be attributed to injecting drug use).[14] Between the Pre-Action and Action Plan periods, the average annual number of tests increased (from 19,058 to 29,045), average annual number of positive tests increased (from 1993 to 2405) and average positivity decreased (from $10.5 \%$ to $8.3 \%$ ). The average annual percentage change in the number of people tested was $5.1 \%$ during the Pre-Action Plan period and $6.1 \%$ during the Action Plan period while the respective average annual percentage change in the number of positives detected was $-2.9 \%$ and $13.4 \%$.

New HCV diagnoses decreased from 1,483 in 1999 to 1,055 in 2006. This trend reversed and increased annually to a peak of 1,967 in 2011. Following very few diagnoses in drug services prior to 2009 , this setting accounted for $12.7 \%$ of diagnoses in 2009, 24.3\% of diagnoses in 2010 and $20.6 \%$ in 2011.

\section{Trends in testing, and testing positive, by setting}

Figure 2 shows the annual number of people tested and the annual number tested positive. Testing in hospitals remained largely stable, and consequently the proportion testing in this setting decreased over time: from $66 \%(10,254)$ in 1999 to $41 \%(12,767)$ in 2011. In drug services, where DBS testing was introduced in 2009, 
there was a six-fold increase in the annual number of people tested from 488 in 2008 to a peak of 1,706 in 2010 followed by a decline to 1,473 in 2011 . In the prison setting, there was also an increase from 288 in 2008 to 571 in 2010 and this level was maintained in 2011.

In general practice testing increased steadily, more than trebling from 3,336 in 1999 to 11,453 in 2011 , while the number of positive tests increased at a lower rate (rising 1.5-1.7 fold, from 422 in 1999 to a peak of 728 in 2011). In NHS Lothian, however, there was a four-fold increase from 66 positives in 1999 to 260 in 2011 . The number of general practices testing increased marginally from 502 requesting tests in 1999 to 538 requesting tests in 2011, accounting for almost all of the practices in these areas. The median number of tests per practice increased from 5 in 1999 to 15 in 2011. 
Table 1: Characteristics of the annual number of people being tested for anti-HCV, and the number who tested positive, during 1999-2011, stratified by pre-Action Plan (1999-2006) and Action Plan (2007-2011) periods

\begin{tabular}{|c|c|c|c|c|c|c|c|c|c|c|c|c|c|}
\hline \multirow{3}{*}{ Characteristic } & & \multicolumn{4}{|c|}{$1999-2011$} & \multicolumn{4}{|c|}{ Pre-Action Plan (1999-2006) } & \multicolumn{4}{|c|}{ Action Plan (2007-2011) } \\
\hline & & \multicolumn{2}{|c|}{ Total } & \multicolumn{2}{|c|}{ Anti-HCV Positive } & \multicolumn{2}{|c|}{$\begin{array}{c}\text { Average Annual } \\
\text { Tests }\end{array}$} & \multicolumn{2}{|c|}{$\begin{array}{c}\text { Average Annual } \\
\text { Positives }\end{array}$} & \multicolumn{2}{|c|}{$\begin{array}{c}\text { Average Annual } \\
\text { Tests }\end{array}$} & \multicolumn{2}{|c|}{$\begin{array}{c}\text { Average Annual } \\
\text { Positives }\end{array}$} \\
\hline & & $\mathrm{N}$ & $\%$ & $\mathrm{n}$ & $\%($ of $\mathrm{N})$ & $\mathrm{N}$ & $\%$ & $\mathrm{n}$ & $\%($ of $\mathrm{N})$ & $\mathrm{N}$ & $\%$ & $\mathrm{n}$ & $\%($ of $\mathrm{N})$ \\
\hline All & & 297689 & - & 27966 & $9.4 \%$ & 19058 & - & 1993 & $10.5 \%$ & 29045 & - & 2405 & $8.3 \%$ \\
\hline \multirow[t]{3}{*}{ Gender } & Female & 130337 & $43.8 \%$ & 9325 & $7.2 \%$ & 8465 & $44.4 \%$ & 678 & $8.0 \%$ & 12524 & $43.1 \%$ & 780 & $6.2 \%$ \\
\hline & Male & 164147 & $55.1 \%$ & 18395 & $11.2 \%$ & 10422 & $54.7 \%$ & 1299 & $12.5 \%$ & 16154 & $55.6 \%$ & 1601 & $9.9 \%$ \\
\hline & Not Reported & 3205 & $1.1 \%$ & 246 & $7.7 \%$ & 17 & $0.1 \%$ & 16 & $94.1 \%$ & 366 & $1.3 \%$ & 24 & $6.6 \%$ \\
\hline \multirow[t]{7}{*}{ Age at first test } & $<20$ & 20613 & $6.9 \%$ & 743 & $3.6 \%$ & 1432 & $7.5 \%$ & 70 & $4.9 \%$ & 1831 & $6.3 \%$ & 36 & $2.0 \%$ \\
\hline & $20-29$ & 61932 & $20.8 \%$ & 6828 & $11.0 \%$ & 3954 & $20.7 \%$ & 588 & $14.9 \%$ & 6061 & $20.9 \%$ & 424 & $7.0 \%$ \\
\hline & $30-39$ & 65590 & $22.0 \%$ & 11050 & $16.8 \%$ & 4145 & $21.7 \%$ & 798 & $19.3 \%$ & 6484 & $22.3 \%$ & 933 & $14.4 \%$ \\
\hline & $40-49$ & 50143 & $16.8 \%$ & 6265 & $12.5 \%$ & 2987 & $15.7 \%$ & 334 & $11.2 \%$ & 5249 & $18.1 \%$ & 719 & $13.7 \%$ \\
\hline & $50-59$ & 38461 & $12.9 \%$ & 1979 & $5.1 \%$ & 2423 & $12.7 \%$ & 108 & $4.5 \%$ & 3815 & $13.1 \%$ & 224 & $5.9 \%$ \\
\hline & $60+$ & 58514 & $19.7 \%$ & 689 & $1.2 \%$ & 3845 & $20.2 \%$ & 48 & $1.2 \%$ & 5551 & $19.1 \%$ & 61 & $1.1 \%$ \\
\hline & NK & 2436 & $0.8 \%$ & 412 & $16.9 \%$ & 271 & $1.4 \%$ & 47 & $17.3 \%$ & 53 & $0.2 \%$ & 8 & $15.1 \%$ \\
\hline \multirow[t]{6}{*}{ Setting } & Hospital & 145140 & $48.8 \%$ & 13118 & $9.0 \%$ & 10536 & $55.3 \%$ & 1043 & $9.9 \%$ & 12170 & $41.9 \%$ & 956 & $7.9 \%$ \\
\hline & GP & 93954 & $31.6 \%$ & 7632 & $8.1 \%$ & 5421 & $28.4 \%$ & 523 & $9.6 \%$ & 10117 & $34.8 \%$ & 690 & $6.8 \%$ \\
\hline & Drug Service & 5399 & $1.8 \%$ & 1959 & $36.3 \%$ & 67 & $0.4 \%$ & 13 & $19.4 \%$ & 973 & $3.3 \%$ & 371 & $38.1 \%$ \\
\hline & Prison & 4200 & $1.4 \%$ & 1490 & $35.5 \%$ & 257 & $1.3 \%$ & 114 & $44.4 \%$ & 429 & $1.5 \%$ & 116 & $27.0 \%$ \\
\hline & GUM Clinic & 33677 & $11.3 \%$ & 1398 & $4.2 \%$ & 1699 & $8.9 \%$ & 88 & $5.2 \%$ & 4018 & $13.8 \%$ & 139 & $3.5 \%$ \\
\hline & Other/Not Known & 15319 & $5.1 \%$ & 2369 & $15.5 \%$ & 1079 & $5.7 \%$ & 212 & $19.6 \%$ & 1338 & $4.6 \%$ & 135 & $10.1 \%$ \\
\hline \multirow[t]{4}{*}{ NHS Board } & $\begin{array}{l}\text { Greater Glasgow \& } \\
\text { Clyde }\end{array}$ & 119786 & $40.2 \%$ & 16945 & $14.1 \%$ & 8257 & $43.3 \%$ & 1242 & $15.0 \%$ & 10746 & $37.0 \%$ & 1402 & $13.0 \%$ \\
\hline & Lothian & 85571 & $28.7 \%$ & 4215 & $4.9 \%$ & 4869 & $25.5 \%$ & 231 & $4.7 \%$ & 9323 & $32.1 \%$ & 473 & $5.1 \%$ \\
\hline & Grampian & 55243 & $18.6 \%$ & 4676 & $8.5 \%$ & 3761 & $19.7 \%$ & 379 & $10.1 \%$ & 5031 & $17.3 \%$ & 329 & $6.5 \%$ \\
\hline & Tayside & 37089 & $12.5 \%$ & 2130 & $5.7 \%$ & 2171 & $11.4 \%$ & 140 & $6.4 \%$ & 3944 & $13.6 \%$ & 201 & $5.1 \%$ \\
\hline \multirow[t]{2}{*}{ Ethnicity } & South Asian & 9332 & $3.1 \%$ & 1048 & $11.2 \%$ & 423 & $2.2 \%$ & 57 & $13.5 \%$ & 1190 & $4.1 \%$ & 119 & $10.0 \%$ \\
\hline & Other & 288357 & $96.9 \%$ & 26918 & $9.3 \%$ & 18636 & $97.8 \%$ & 1936 & $10.4 \%$ & 27854 & $95.9 \%$ & 2286 & $8.2 \%$ \\
\hline \multirow[t]{3}{*}{ Risk } & PWID Reported & 25580 & $8.6 \%$ & 9362 & $36.6 \%$ & 1702 & $8.9 \%$ & 599 & $35.2 \%$ & 2392 & $8.2 \%$ & 914 & $38.2 \%$ \\
\hline & Not Reported & 272109 & $91.4 \%$ & 18604 & $6.8 \%$ & 17356 & $91.1 \%$ & 1393 & $8.0 \%$ & 26652 & $91.8 \%$ & 1492 & $5.6 \%$ \\
\hline & & \multicolumn{12}{|c|}{ Average Annual Percentage Change } \\
\hline Trend in Testing* & $\begin{array}{l}\text { Percentage change } \\
95 \% \mathrm{Cl}\end{array}$ & \multicolumn{2}{|c|}{$\begin{array}{c}6.4 \% \\
6.3 \text { to } 6.5\end{array}$} & \multicolumn{2}{|c|}{$\begin{array}{c}2.3 \% \\
2.0 \text { to } 2.6\end{array}$} & \multicolumn{2}{|c|}{$\begin{array}{c}5.1 \% \\
4.8 \text { to } 5.3\end{array}$} & \multicolumn{2}{|c|}{$\begin{array}{c}-2.9 \% \\
-3.5 \text { to }-2.2\end{array}$} & \multicolumn{2}{|c|}{$\begin{array}{c}6.1 \% \\
5.7 \text { to } 6.5\end{array}$} & \multicolumn{2}{|c|}{$\begin{array}{c}13.4 \% \\
12.0 \text { to } 14.9\end{array}$} \\
\hline
\end{tabular}

* Trends calculated using Poisson Regression 


\section{Trends in testing associated with the Action Plan: Segmented regression}

Results of the segmented negative binomial regression analysis are shown in Table 2, with associated graphs in appendices 2 and 3. In the Pre-Action Plan period, the overall trend in the number of tests was significantly increasing $(\mathrm{R} R=1.03$ per 6month period). This was reflected across GP, drug services and GUM clinics; in prisons there was a decreasing trend $(\mathrm{RR}=0.94)$ and no significant change in trend was observed in the hospital setting. There was a significant increase overall in level change in outcomes (i.e. the number of tests) at the start of the Action Plan period $(\mathrm{RR}=1.09)$ with only the GUM and prisons showing a significant level change in the number of tests $(\mathrm{RR}=1.42$ and $\mathrm{RR}=1.32$, respectively). Overall, there was no significant change in the trend in testing during the Action Plan period, compared to the pre-Action period. However, there was a significantly increasing trend in testing during the Action Plan, compared to pre-Action Plan period within prison $(\mathrm{R}=1.19)$, drug services $(R R=1.11)$, and hospital $(R R=1.01)$; while there were significantly reduced trends within $\mathrm{GP}(\mathrm{RR}=0.98)$ and $\mathrm{GUM}$ clinics $(\mathrm{RR}=0.87)$.

\section{Trends in testing positive associated with the Action Plan: Segmented regression}

In the Pre-Action Plan period, the trend in positive tests was significantly decreasing overall $(\mathrm{RR}=0.98)$ and across most settings, with the exception of an increasing trend in $\mathrm{GP}(\mathrm{RR}=1.03)$ and drug services $(\mathrm{RR}=1.10)$; although the numbers in this latter setting were low. Only in the GUM setting was there a significant level change in the number of positive tests at the start of the Action Plan $(\mathrm{RR}=1.76)$. The change in trend between the two periods was significantly increased in all settings except general practice, and had increased the most in drug services $(\mathrm{RR}=1.43)$. 
Table 2: Results of negative binomial segmented regression analysis to identify 1) effect of HCV action plan on testing outcomes by setting and 2) the introduction of dried blood spot testing on testing outcomes; between 1999 and 2011

\begin{tabular}{|c|c|c|c|c|c|c|c|}
\hline & \multicolumn{2}{|l|}{ Initial Trend } & \multicolumn{2}{|c|}{ Level Change in Outcomes } & \multicolumn{2}{|c|}{ Change in trend } & \multirow{2}{*}{$\begin{array}{l}\text { Post Trend } \\
\text { RR }(95 \% \mathrm{Cl})\end{array}$} \\
\hline & $\mathrm{RR}(95 \% \mathrm{Cl})$ & $p$ value & RR $(95 \% \mathrm{Cl})$ & p value & RR $(95 \% \mathrm{CI})$ & p value & \\
\hline Model 1 & \multicolumn{2}{|c|}{ Pre-Action 1996-2006 } & \multicolumn{2}{|c|}{ Start of Action Plan } & \multicolumn{2}{|c|}{ Change in Trend* } & Action Plan 2007-2011 \\
\hline \multicolumn{8}{|l|}{$\begin{array}{l}\text { a) Annual Number of } \\
\text { People Tested }\end{array}$} \\
\hline $\begin{array}{l}\text { All Settings } \\
\text { General }\end{array}$ & $1.025(1.020-1.030)$ & $<0.001$ & $1.092(1.016-1.174)$ & 0.016 & $1.003(0.993-1.014)$ & 0.558 & $1.028(1.012-1.044)$ \\
\hline Practice & 1.059 (1.053-1.065) & $<0.001$ & $1.023(0.939-1.115)$ & 0.596 & $0.979(0.967-0.991)$ & 0.001 & $1.037(1.018-1.056)$ \\
\hline Drug Services & 1.146 (1.100-1.197) & $<0.001$ & $1.472(0.817-2.654)$ & 0.198 & 1.108 (1.016-1.209) & 0.021 & $1.270(1.115-1.446)$ \\
\hline Prison & $0.943(0.927-0.961)$ & $<0.001$ & $1.320(1.004-1.736)$ & 0.047 & $1.191(1.146-1.239)$ & $<0.001$ & $1.124(1.062-1.190)$ \\
\hline GUM Clinic & 1.115 (1.101-1.130) & $<0.001$ & $1.420(1.167-1.727)$ & $<0.001$ & $0.870(0.845-0.895)$ & $<0.001$ & $0.970(0.930-1.012)$ \\
\hline Hospital & 1.004 (0.999-1.010) & 0.127 & $1.021(0.937-1.112)$ & 0.637 & $1.014(1.001-1.027)$ & 0.03 & 1.018 (1.000-1.037) \\
\hline \multicolumn{8}{|l|}{$\begin{array}{l}\text { b) Annual number of } \\
\text { people tested positive }\end{array}$} \\
\hline $\begin{array}{l}\text { All Settings } \\
\text { General }\end{array}$ & $0.981(0.970-0.992)$ & 0.001 & $0.888(0.747-1.056)$ & 0.18 & $1.102(1.075-1.131)$ & $<0.001$ & $1.081(1.042-1.122)$ \\
\hline Practice & $1.033(1.024-1.043)$ & $<0.001$ & $0.987(0.861-1.132)$ & 0.856 & $0.987(0.967-1.007)$ & 0.188 & $1.020(0.990-1.050)$ \\
\hline Drug Services & 1.101 (1.025-1.182) & 0.008 & $0.711(0.273-1.849)$ & 0.484 & $1.432(1.246-1.646)$ & $<0.001$ & 1.577 (1.277-1.946) \\
\hline Prison & $0.920(0.897-0.943)$ & $<0.001$ & $1.014(0.681-1.511)$ & 0.944 & 1.228 (1.161-1.299) & $<0.001$ & 1.130 (1.042-1.225) \\
\hline GUM Clinic & $0.973(0.953-0.994)$ & 0.011 & 1.761 (1.304-2.379) & $<0.001$ & $1.054(1.011-1.100)$ & 0.016 & $1.025(0.962-1.093)$ \\
\hline Hospital & $0.971(0.956-0.987)$ & $<0.001$ & $0.857(0.668-1.101)$ & 0.228 & $1.076(1.037-1.116)$ & $<0.001$ & $1.045(0.991-1.102)$ \\
\hline Model 2 & \multicolumn{2}{|c|}{ Pre-DBS 1999-2009 } & \multicolumn{2}{|c|}{ Introduction of DBS Testing } & \multicolumn{2}{|c|}{ Change in Trend $^{\dagger}$} & DBS Period 2009-2011 \\
\hline \multicolumn{8}{|l|}{$\begin{array}{l}\text { c) Annual Number of } \\
\text { People Tested }\end{array}$} \\
\hline All Settings & $1.030(1.027-1.034)$ & $<0.001$ & $1.118(1.009-1.223)$ & 0.034 & 0.970 (0.942-0.999) & 0.042 & $1.000(0.968-1.033)$ \\
\hline Drug Services & $1.184(1.154-1.215)$ & $<0.001$ & 3.445 (1.1748-6.787) & $<0.001$ & $0.840(0.695-1.016)$ & 0.072 & $0.995(0.802-1.234)$ \\
\hline \multicolumn{8}{|l|}{$\begin{array}{l}\text { d) Annual number of } \\
\text { people tested positive }\end{array}$} \\
\hline All Settings & 0.989 (0.981-0.996) & 0.003 & $1.670(1.322-2.111)$ & $<0.001$ & $1.014(0.950-1.083)$ & 0.671 & 1.003 (0.932-1.079) \\
\hline Drug Services & $1.139(1.103-1.176)$ & $<0.001$ & $12.050(6.350-22.904)$ & $<0.001$ & $0.862(0.725-1.027)$ & 0.096 & $0.982(0.799-1.208)$ \\
\hline
\end{tabular}

${ }^{*}$ Change in trend in the Action Plan Period (2007-2011), compared to Pre-Action Plan period

${ }^{+}$Change in trend in the DBS Period (July 2009 to December 2011), compared to Pre DBS period (January 1999 to June 2009) 


\section{Trends associated with the introduction of DBS testing: Segmented regression}

The second model, examining the introduction of DBS testing, found an increasing pre-intervention trend in testing in drug services $(R R=1.18)$ with a significant three-fold increase in testing during 2009 ( $R R=3.45)$. Prior to DBS testing, the trend in positive tests was similarly increasing in drug services $(R R=1.14)$ but the level change in the number of positive tests during 2009 was greater, with a twelve-fold increase. Following the introduction of DBS testing, there were no significant trends although there were a limited number of data points following the change point in this model.

\section{DISCUSSION}

This is the first study to examine HCV testing practice in the context of a major government policy and investment. The Hepatitis C Action Plan for Scotland has been described as an example of best practice in the Global Commission on Drug Policy 2013 report "The Hidden Hepatitis C Epidemic".[15] A key aim was to identify undiagnosed infections and through increases in testing and diagnoses observed, the proportion undiagnosed reduced from $62 \%$ in 2006 to $45 \%$ in 2013. [1, 6] As a result, Scotland is now among a small number of countries where the majority of hepatitis $\mathrm{C}$ infected people have been diagnosed.[16]

The greatest impact was through introduction of Dried Blood Spot (DBS) testing in community drug services. Given previously negligible levels of diagnosis in this setting, the significant increase in testing described can be attributed to DBS testing. This has driven the overall increases in new diagnoses observed since 2009, with drug services now referring approximately $20 \%$ of new diagnoses each year compared with $<1 \%$ before the introduction of DBS testing.[9] In a randomised controlled cluster study in specialist drug clinics and prisons in England and Wales during 2004, services utilising DBS testing undertook 14.5\% 
more $\mathrm{HCV}$ testing than those employing standard testing methods.[17] Following introduction of DBS testing at substance misuse services in Wales, a six-fold increase in testing was also observed. [18] DBS testing overcomes the need for a venous blood sample, a known barrier to testing among PWID due to damaged veins, and requirement of a clinician to take the sample. Therefore availability of testing to those at the greatest risk of infection, who may not see a GP but are attending harm reduction or other drug services is increased.[17-19]

DBS screening for $\mathrm{HCV}$ in drug services has previously been estimated to be costeffective within standard UK willingness-to-pay thresholds while in prisons it is cost effective when antiviral treatment is completed in at least $40 \%$ of cases.[20]

McDonald et al. found variation between diagnosis setting and attendance at specialist liver clinics; with $60 \%$ of those diagnosed in general practice attending within twelve months compared with $40 \%$ among those diagnosed through drug services.[21] This may indicate a more established patient pathway, allowing patients to be referred to specialist care by their GP, or differences among individuals diagnosed in different settings.

Testing and case-finding for $\mathrm{HCV}$ in general practice, therefore, remains important and was a major focus of both the Action Plan and pre-Action Plan initiatives, as previously discussed. Based solely on analysis of the testing data we have found no evidence of an impact. Testing in primary care increased throughout the observation period but during the Action Plan did so at a lower level and new diagnoses remained largely stable, suggesting GPs are testing more patients who are at low risk of infection.[9]

A 2007 needs assessment found that $80 \%$ of GPs reported not routinely asking patients about risk factors for HCV.[6] More recently, a mixed methods analysis of HCV case finding in England identified similar barriers with GPs reporting confidence in their knowledge of HCV but remembering to offer a test was an issue. They suggested IT systems 
be improved to prompt GPs to offer a test to at risk patients.[22] However, a study of HCV screening in general practice found several reasons why patients may decline a test when offered; including not recognising risk and poor venous access.[23] Only in NHS Lothian, where many drug services are delivered through general practice, was an increase in positive tests and diagnoses in recent years found.

Identifying undiagnosed $\mathrm{HCV}$-infected individuals remains a key issue. Most screening strategies rely on a targeted approach based on the ascertainment of risk factors.[4, 23- 26] Recently the Centres for Disease Control (CDC), citing the limitations of this approach, have recommended birth cohort screening in the United States for those born during 1945-1965.[27] Here, we have demonstrated that offering HCV testing in services designed for those at the highest risk, i.e. drug services, can be valuable for case-finding. However, following a peak in testing in 2010, there was a decrease in 2011. . There are approximately 3,000 new clients attending drug services in four largest NHS boards per year who report a history of injecting.[28] This represents a maximum threshold of coverage in this setting, while only $49 \%$ of PWID interviewed at services providing injection equipment in 2011 reported being tested for HCV in the last year.[1] Expansion of DBS testing settings may increase coverage and settings where PWID can be identified, such as pharmacies dispensing methadone, could be considered.

It has been established that identification of former PWID can be made in general practice, particularly in practices of high social deprivation, and that the offer of HCV testing is generally accepted in this group.[23, 24] The availability of DBS testing in primary care, therefore, may overcome barriers such as poor venous access and this should also be considered.[22] A combination of DBS testing for PWID engaging with drug services and improved targeted case finding of former PWID by GPs may be preferable to adopting a birth cohort screening approach.. 
Segmented regression has been used to examine the impact of a wide variety of real world events such as policy changes, public health initiatives or environmental exposure.[2931] The main strength of this methodology is that it has been possible to examine changes in testing activity prior to, at the time of and following the launch of the Action Plan and the introduction of DBS testing.

There are a number of limitations to a study of this nature. In particular, identification of duplicate tests for an individual using electronic matching and limited identifiers. Four matching criteria were employed to try to ensure duplicate tests were identified. Due to lack of risk information it has not been possible to describe, or analyse, testing among recommended groups.[2- 4] Aside from national initiatives described in Appendix 1, there have also been local initiatives, perhaps at NHS board or service level; increased press attention and additions to the scientific literature in this field. It is consequently difficult to evaluate a discrete intervention using testing data alone.

Despite these limitations, this study highlights the impact of a National Action Plan on testing and case-finding of HCV. While previous initiatives focused almost exclusively on testing by GPs, new approaches in the form of DBS testing by other community setting practitioners have resulted in an increase in testing and diagnoses at the national level that have not been elsewhere demonstrated. These findings can be used, and improved on, by other countries where $\mathrm{HCV}$ is a public health priority. 


\section{WHAT IS ALREADY KNOWN ON THIS SUBJECT?}

- In most resource rich countries, the majority of chronic hepatitis $\mathrm{C}$ infections remain undiagnosed; this is a key challenge in the control and management of the epidemic

- Barriers to testing have been previously ascertained. Among patients these include poor awareness of the disease, fear of stigma or treatment and not engaging with health service. Among professionals barriers include lack of time for consultations, not routinely ascertaining risk activities and poor venous access.

\section{WHAT THIS STUDY ADDS?}

- Dried blood spot sampling in community drug services improves hepatitis C case finding in those at risk of infection by overcoming the established barriers to testing such as poor veins or limited contact with health services.

- No evidence of an impact of awareness raising activities in GPs was found although general practice accounts for a significant proportion of testing and diagnosis. 


\section{REFERENCES}

1. Hepatitis C in the UK 2014. London: Health Protection Agency Centre for Infections, July 2014

2. Scottish Needs Assessment Programme. Hepatitis C. Glasgow: Office for Public Health in Scotland, 2000

3. Proceedings of the Consensus Conference on Hepatitis C. April 21-22 2004. Edinburgh, United Kingdom. J Viral Hepat. 2004,11(Suppl.1)1-39

4. Scottish Intercollegiate Guidelines Network (SIGN). Management of hepatitis C.

Guideline No. 92. December 2006. ISBN 9781905813025

5. Scottish Government. Hepatitis C Action Plan for Scotland: Phase I (September 2006April 2008. Edinburgh. Scottish Government; 2006. Available from:

http://www.scotland.gov.uk/Publications/2006/09/15093626/0

6. Scottish Government. Hepatitis C Action Plan for Scotland: Phase II (May 2008-March 2011). Edinburgh. Scottish Government; 2008. Available from:

http://www.scotland.gov.uk/Publications/2008/05/13103055/0

7. Judd A, Parry J, Hickman H, et al. Evaluation of a modified commercial assay in detecting antibody to hepatitis C virus in oral fluids and dried blood spots. J Med Virol. 2003

Sep;71(1):49-55.

8. Bennett S, Gunson RN, McAllister GE, et al. Detection of hepatitis C virus RNA in dried blood spots. J Clin Virol. 2012 Jun;54(2):106-9. doi: 10.1016/j.jcv.2012.02.004.

9. McLeod A, Hutchison S, Goldberg D. Surveillance of known hepatitis C antibody positive cases in Scotland: results to 31 December 2012. Health Protection Scotland. 2013;47(18)

10. Cummins C, Winter H, Cheng KK, et al. An assessment of the Nam Pehchan computer program for the identification of names of south Asian ethnic origin. J Public Health Med. 1999 Dec; 21 (4):401-6.

11. England K, Pembrey L, Tovo PA, et al. European Paediatric HCV Network. Excluding hepatitis $\mathrm{C}$ virus (HCV) infection by serology in young infants of $\mathrm{HCV}$-infected mothers. Acta Paediatr. 2005 Apr; 94(4):444-50. Erratum in: Acta Paediatr. 2005 Jun 94(6):814

12. Wagner AK, Soumerai SB, Zhang F, et al. Segmented regression analysis of interrupted time series studies in medication use research. J Clin Pharm Ther. 2002 Aug;27(4): 299-309

13. Ver Hoef JM, Boveng PL. Quasi-Poisson vs. negative binomial regression: how should we model overdispersed count data? Ecology. 2007 Nov;88(1): 2766-72.

14. McDonald SA, Hutchinson SJ, Schnier C, et al. Estimating the number of injecting drug users in Scotland's HCV-diagnosed population using capture-recapture methods. Epidemiol Infect. 2014 Jan; 142(1):200-7 . doi: 10.1017/S0950268813000617. 
15. The Negative Impact of the War on Drugs on Public Health: The Hidden Hepatitis C Epidemic. Global Commission on Drug Policy. May 2013

16. Cornberg M, Razavi HA, Alberti A, et al. A systematic review of hepatitis $\mathrm{C}$ virus epidemiology in Europe, Canada and Israel. Liver Int. 2011 Jul;31 Suppl 2:30-60. doi: 10.1111/j.1478-3231.2011.02539.x.

17. Hickman M, McDonald T, Judd A, et al. Increasing the uptake of hepatitis $\mathrm{C}$ virus testing among injecting drug users in specialist drug treatment and prison settings by using dried blood spots for diagnostic testing: a cluster randomized controlled trial. J Viral Hepat. 2008 Apr;15(4):250-4.

18. Craine N, Parry J, O'Toole J, et al. Improving blood-borne viral diagnosis; clinical audit of the uptake of dried blood spot testing offered by a substance misuse service. $J$ Viral Hepat. 2009 Mar;16(3):219-22 . doi: 10.1111/j.1365-2893.2008.01061.x.

19. Hope VD, Hickman M, Ngui SL, et al. Measuring the incidence, prevalence and genetic relatedness of hepatitis $\mathrm{C}$ infections among a community recruited sample of injecting drug users, using dried blood spots, J Viral Hepat., 2011 Apr;18(4):262-70. doi: 10.1111/j.13652893.2010.01297.x.

20. Martin NK, Hickman M, Miners A, et al. Cost-effectiveness of HCV case-finding for people who inject drugs via dried blood spot testing in specialist addiction services and prisons. BMJ Open. 2013 Aug 13;3(8). doi: 10.1136/bmjopen-2013-003153.

21. McDonald SA, Hutchinson SJ, Innes HA, et al. Attendance at specialist hepatitis clinics and initiation of antiviral treatment among persons chronically infected with hepatitis $\mathrm{C}$ : examining the early impact of Scotland's Hepatitis C Action Plan. J Viral Hepat. 2014 May;21(5):366-76. doi: 10.1111/jvh.12153.

22. Datta S, Horwood J, Hickman M, et al. Case-finding for hepatitis C in primary care: a mixed-methods service evaluation. Br J Gen Pract. 2014 Feb;64(619):e67-74. doi: 10.3399/bjgp14X677112.

23. Cullen BL, Hutchinson SJ, Cameron SO, et al. Identifying former injecting drug users infected with hepatitis $\mathrm{C}$ : an evaluation of a general practice-based case-finding intervention. J Public Health (Oxf). 2012 Mar;34(1):14-23. doi: 10.1093/pubmed/fdr097.

24. Anderson EM, Mandeville RP, Hutchinson SJ, et al. Evaluation of a general practice based hepatitis C virus screening intervention. Scott Med J. 2009 Aug;5(3):3-7

25. National Institute for Health and Care Excellence (2012) Hepatitis B and C: ways to promote and offer testing to people at increased risk of infection. PH43. London: National Institute for Health and Care Excellence

26. CDC. Recommendations for prevention and control of hepatitis $\mathrm{C}$ virus (HCV) infection and HCV-related chronic disease. MMWR 1998;47(No. RR-19) 
27. Smith BD, Morgan RL, Beckett GA, et al. Centers for Disease Control and Prevention. Recommendations for the identification of chronic hepatitis $\mathrm{C}$ virus infection among persons born during 1945-1965. MMWR Recomm Rep. 2012 Aug 17;61(RR-4):1-32

28. Information Services Division. Drug Misuse Statistics Scotland 2011. Edinburgh. 2012 29. Langley T, Szatkowski L, Lewis S, et al. The freeze on mass media campaigns in England: a natural experiment of the impact of tobacco control campaigns on quitting behaviour. Addiction. 2013 Dec 11. doi: 10.1111/add.12448. (Epub ahead of print)

30. Lopez Bernal JA, Gasparrini A, Artundo CM, et al. The effect of the late 2000s financial crisis on suicides in Spain: an interrupted time-series analysis. Eur J Public Health. 2013 Oct;23(5):732-6. doi: 10.1093/eurpub/ckt083.

31. Bastuji-Garin S, Sbidian E, Gaudy-Marqueste C, et al. European Dermatology Network (EDEN). Impact of STROBE statement publication on quality of observational study reporting: interrupted time series versus before-after analysis. PLoS One. 2013 Aug 26;8(8):e64733. doi: 10.1371/journal.pone.0064733 


\section{FIGURE/TABLE LEGENDS}

Figure 1: Annual number of people (a) tested for anti-HCV and (b) newly diagnosed with anti- HCV in Scotland's four largest health boards during 1999-2011, by setting.

Figure 2: Annual number of people tested for anti-HCV and number tested positive in Scotland's four largest health boards by setting, 1999-2011

Table 1: Characteristics of the annual number of people being tested for anti-HCV, and the number who tested positive, during 1999-2011, stratified by pre-Action Plan (1999-2006) and Action Plan (2007-2011) periods

Table 2: Results of negative binomial segmented regression analysis to identify 1) effect of $\mathrm{HCV}$ action plan on testing outcomes by setting and 2) the introduction of dried blood spot testing on testing outcomes; between 1999 and 2011 